\title{
Effect of smartphone usage profiles on addiction in a university student: a cross-sectional study
}

\author{
Deniz Adnan Coban $^{1 \oplus}$, Ibrahim Gundogmus ${ }^{2}{ }^{\circledR}$ \\ ${ }^{1}$ Neuropsychiatry Center of the Health \& Training Academy (HTA), Istanbul - Turkey \\ 2University of Health Sciences, Gulhane Faculty of Medicine, Department of Psychiatry, Ankara - Istanbul - Turkey
}

\begin{abstract}
Objective: With their rich content, smartphones have become an indispensable part of today's life. In spite of the convenience they contribute to our daily lives, one of the most important problems is smartphone addiction associated with the user losing control. Although the results of smartphone addiction are partially known, there is only a limited number of studies explaining the addictive content and smartphone usage profiles. The aim of this study was to determine the smartphone usage profiles and their intended use and to investigate the extent to which their intended use effects smartphone addiction in a group selected from university student populations.

Method: The study was carried out with 1465 university students ( 861 female and 604 male) who had been using smartphones for the last year. Data were collected through standardized, anonymous, self-report online data surveys. All participants were administered a socio-demographic data form and the Smartphone Addiction Scale-Short Version.

Results: As a result of the analysis, it was found that using the smartphone for "social media use" and "meeting new friends" increased the risk of smartphone addiction. "Use for studying/academic purpose" and "use to follow the news" decreased the risk of addiction. Male students, were found to use smartphones more for "playing games," "to meet new friends," and "to follow the news" than female students.

Conclusion: In our study, smartphone addiction has been associated with certain smartphone usage purposes. In the study, "social media use" and "meeting new friends" on smartphones were the most powerful predictors of smartphone addiction for students while "use for studying/academic purpose" and "to follow the news" were found to be predictors of reduced risk of addiction.
\end{abstract}

Keywords: Behavioral addiction, smartphone addiction, social media networks

\section{INTRODUCTION}

Smartphones are popular mobile devices, usually with a touchscreen, containing a large number of features allowing for communication, accessing the internet and social networks, messaging, video, games, taking photographs, using multimedia, and navigation.
According to a multi-center study that also included Turkey, the smartphone is the electronic device with the largest ownership at a rate of $92 \%$ (1). Among the European countries included in the study, the one with the greatest use of smartphones turned out to be Turkey, where users on average check their phone 78 times per day (European mean: 48), 79\% check their

How to cite this article: Coban DA, Gundogmus I. Effect of smartphone usage profiles on addiction in a university student: a cross-sectional study. Dusunen Adam The Journal of Psychiatry and Neurological Sciences 2019;32:87-94.

Correspondence: Ibrahim Gundogmus, University of Health Sciences, Gulhane Faculty of Medicine, Department of Psychiatry, Ankara, Istanbul - Turkey

Phone: +90 5455870575 E-mail: dribrahim06@gmail.com

Received: December 05, 2018; Revised: March 11, 2018; Accepted: March 14, 2019 
phone in the first 15 minutes after waking up (European mean: 62\%), $72 \%$ check their phone in the last 15 minutes before going to be (European mean: $53 \%$ ), and $85 \%$ check their phones in bed during the night for whatever reason (European mean: 48\%) (1). These results demonstrate that smartphones, with their main characteristic being internet-based applications, can lead to excessive and uncontrolled use with detrimental outcomes especially in a nation like Turkey where the young make up a large share of the population (2). Though the smartphone offers great convenience for our daily lives, its use may be problematic, the greatest problem being smartphone addiction, where smartphone users lose control over their consumption (3).

With the common use of technology and technological devices, pathological use has developed at the same time. There is a great number of studies in the literature proposing the diagnosis of smartphone addiction $(4,5)$. Although there are evidence-based studies, smartphone addiction has not yet been included in the Diagnostic and Statistical Manual of Mental Disorders (DSM-5) and there are no official instruments available to measure the condition. Defining behavioral addictions, including smartphone addiction, is actually difficult as it includes not only physical dependency but also involves social and psychological factors (6). Among the basic characteristics of behavioral addictions are the following: continuing to busy oneself with a certain behavior despite of negative effects, using this behavior to escape from reality or to create a feeling of euphoria, developing tolerance in the continuation of the behavior, sensing withdrawal symptoms in its absence, incurring interpersonal problems due to the incessant behavior, and relapse into it (7). Due to the problems it causes, smartphone addiction is becoming more of a public health issue every day. Thus, studies have shown negative effects of problematic smartphone use including a reduced quality of sleep $(7,8)$, depression $(8)$, anxiety $(8)$, poor academic performance (9), problems in the recognition and expression of feelings (10), relational disharmony (10), and fatigue (7). While the increasing use of smartphones in daily life triggered a significant amount of research, we found that the number of studies dealing with the causes of smartphone addiction in the Turkish university student population and their smartphone use profiles is very limited.

The aim of our study is to present smartphone use profiles in the Turkish university student population and the purposes of phone use. In addition, we aim to determine which purposes of smartphone use increase the addiction risk and if there is a difference in purpose between the sexes.

\section{METHOD}

This cross-sectional study was carried out in 2017 at the Neuropsychiatry Center of the Health \& Training Academy (HTA). Enrolled in the study were students from various universities in Istanbul (Health Sciences University, Istanbul University, Dogus University, and Halic University) who had been using a smartphone for at least 1 year. Individuals with any diagnosis of a psychiatric disease or outside the age bracket of 18-65 years were not included in the study. We invited 3620 students to participate, of whom 1968 refused to be enrolled and 187 participants had to be excluded because they had not completed the survey or filled in the form only partly. In the end, 1465 university students in formal education who volunteered to participate were included in the study (Figure 1). Approval from the local ethics committee was obtained before beginning the study, and all volunteers gave their consent before completing the survey. Our study conforms to Helsinki standards.

Data were collected with standardized, anonymous self-report survey forms. All participants were surveyed online with a sociodemographic form requesting personal information, smartphone habits, educational information and details about smartphone use. The participants were invited through a web link. To prevent multiple participation, the mail addresses of all participants were recorded. To determine their

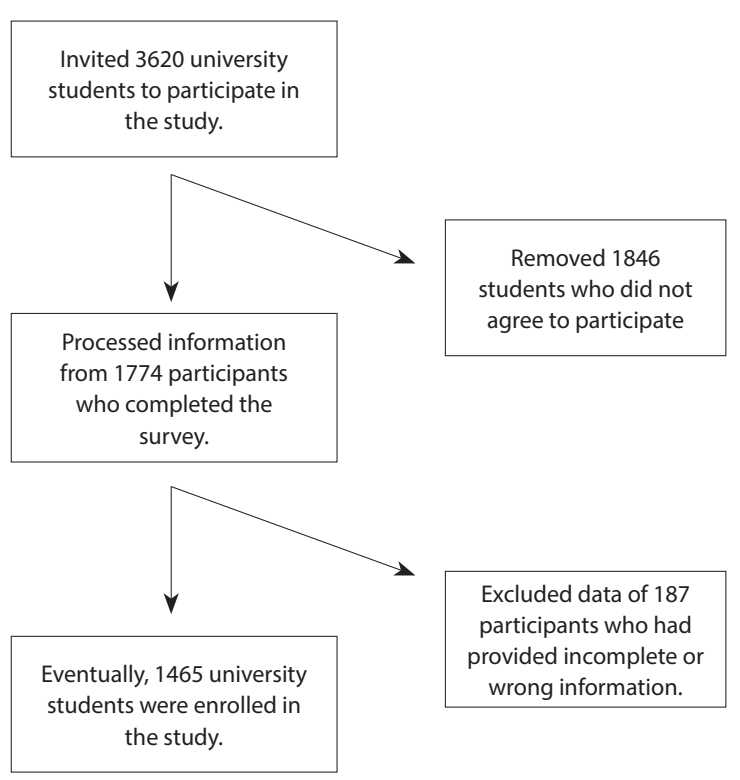

Figure 1: Flowchart of the study. 
smartphone addiction status, all volunteers were administered the Smartphone Addiction Scale-Short Version (SAS-SV) and a form prepared by the researchers for this study in line with the literature to examine the purposes of smartphone use. After the survey, the data were recorded as regular data sets and analyzed.

Smartphone addiction was measured with the SAS$\mathrm{SV}$, an instrument consisting of 10 items rated on a Likert-type scale from 1 (completely disagree) to 6 (completely agree), resulting in a total score between 10 and 60. High scores are correlated with smartphone addiction during the past year (4). A validity and reliability study for the Turkish version was carried out by Noyan et al. (11) finding a Cronbach's alpha coefficient of 0.867 . Kwon et al. (4) reported cutoff points for smartphone addiction of $\geq 31$ for males and $\geq 33$ for females. These values were used for smartphone addiction.

In addition to the SAS-SV, questions were asked about demographic information, age, sex, education level, living circumstances, and smartphone use. After a review of the literature, participants' smartphone use profiles were investigated determining the most common purposes for smartphone use (5,12-14). The participating university students' family income was classified according to data from the Turkish Statistical Institute as "low" if below the hunger limit, "intermediate" if between hunger limit and poverty line, and "high" if above the poverty line. Participants were requested to rank their phone bills as "low," "intermediate," "high," or "very high" according to their own judgment.

\section{Statistical Analysis}

Data analysis was performed with SPSS version 20.0 (Chicago IL, USA). Study participants' sociodemographic characteristics (sex, age, education level) were analyzed descriptively; numerical variables were presented as mean \pm standard deviation, categorical variables as frequency and percentage. To establish if parametric or non-parametric tests could be used, data were first tested for normal distribution. For variables conforming to normal distribution, Student's t-test was used. To compare differences between categorical variables, chisquare test was applied. Logistic regression analysis was used between multiple variables. A value of $p \leq 0.05$ was accepted as statistically significant.

\section{RESULTS}

The sociodemographic and smartphone use characteristics of the 1465 students enrolled in the study are presented in Table 1. Of these students, 861 (58.8\%) were female and $604(41.2 \%)$ male. Statistically significant differences between the sexes were found for the following sociodemographic characteristics: age $(\mathrm{p}<0.001)$, height $(\mathrm{p}<0.001)$, weight $(\mathrm{p}<0.001)$, Body Mass Index $(\mathrm{p}<0.001)$, faculty of study $(\mathrm{p}<0.001)$, living circumstances $(p<0.001)$, and monthly phone bill $(p<0.05)$. Income level, frequency of changing phones, and phone addiction were not statistically significant $(\mathrm{p}>0.05)$.

Regarding students' purpose for using the smartphone, a statistically significant difference between female and male participants was found for playing games $(p<0.001)$, meeting new friends $(\mathrm{p}<0.001)$, and following the news $(\mathrm{p}<0.05)$ (Table 2$)$. For the other purposes (social media use, use for studying/academic purpose, messaging, entertainment [watching series, movies, clips], and shopping), there was no statistically significant difference $(\mathrm{p}>0.05)$.

The effect of phone use profiles on the SAS-SV scores is presented in Table 3. In students using smartphones mainly "for social media" and "to meet new friends," SAS-SV scores were statistically significantly elevated for females $(p<0.001)$, males $(\mathrm{p}<0.001)$, and the total sample $(\mathrm{p}<0.001)$. For the profiles "use for studying/academic purpose" and "messaging," SAS-SV scores were statistically significant for the total sample and for female students $(\mathrm{p} \leq 0.05)$, but not significant for male students $(p>0.05)$. For the "playing games" profile, SAS-SV scores were statistically significant only for male students $(p \leq 0.05)$, while for the total sample and female students, scores were not significant ( $p>0.05)$. SAS-SV scores for "shopping" were statistically significant overall $(\mathrm{p} \leq 0.05)$, but SAS-SV scores for "entertainment" use turned out not to be statistically significant $(\mathrm{p}>0.05)$.

Table 4 presents the effect of smartphone use purposes on addiction for female and male students and for the whole sample, using logistic regression. The results show that for all participants, "social media use" and "meeting new friends" profiles increase the risk of smartphone addiction the most, while "shopping" has the lowest effect $(\mathrm{p} \leq 0.05)$. In female students, the smartphone addiction risk is increased by "social media use," "studying/academic purpose," "playing games," "meeting new friends," and "following the news" $(\mathrm{p} \leq 0.05)$, while in male students, "social media use," "meeting new friends," and "entertainment" increase the addiction risk $(\mathrm{p} \leq 0.05)$. 
Table 1: Participants' sociodemographic and mobile phone use characteristics

\begin{tabular}{|c|c|c|c|c|c|c|c|c|}
\hline \multirow[b]{2}{*}{ Variables } & \multicolumn{2}{|c|}{ Total } & \multicolumn{2}{|c|}{ Male } & \multicolumn{2}{|c|}{ Female } & \multirow[b]{2}{*}{$t / \chi^{2}$} & \multirow[b]{2}{*}{$\mathbf{p}$} \\
\hline & $\mathbf{n}$ & $\%$ & $\mathbf{n}$ & $\%$ & $\mathbf{n}$ & $\%$ & & \\
\hline All participants & 1465 & & 604 & 41.2 & 861 & 58.8 & & \\
\hline Age (Mean \pm SD) & 21.10 & 1.99 & 21.47 & 2.12 & 20.84 & 1.85 & 1185 & $<0.001$ \\
\hline Height (Mean \pm SD) & 170.19 & 8.91 & 177.84 & 6.52 & 164.83 & 5.96 & 1463 & $<0.001$ \\
\hline Weight (Mean \pm SD) & 65.42 & 14.31 & 75.72 & 13.77 & 58.19 & 9.41 & 998 & $<0.001$ \\
\hline BMI & 22.41 & 3.52 & 23.86 & 3.57 & 21.39 & 3.11 & 1181 & $<0.001$ \\
\hline Underweight ( $\leq 18.4)$ & 138 & 9.4 & 19 & 13.8 & 119 & 86.2 & 147519 & $<0.001$ \\
\hline Normal weight (18.5-24.9) & 1034 & 70.6 & 382 & 36.9 & 652 & 63.1 & & \\
\hline Pre-obesity (25-29.9) & 241 & 16.0 & 171 & 71.0 & 70 & 29.0 & & \\
\hline Obese $(\geq 30)$ & 52 & 3.5 & 30 & 61.5 & 20 & 38.5 & & \\
\hline \multicolumn{9}{|l|}{ Faculty } \\
\hline Medical/dental & 205 & 14.0 & 80 & 39.0 & 125 & 61.0 & 154917 & $<0.001$ \\
\hline Law & 73 & 5.0 & 22 & 30.1 & 51 & 69.9 & & \\
\hline Engineering & 333 & 22.7 & 202 & 60.7 & 131 & 39.3 & & \\
\hline Education & 102 & 7.0 & 26 & 24.5 & 76 & 75.5 & & \\
\hline Economics/administr. & 199 & 13.6 & 100 & 50.3 & 99 & 49.7 & & \\
\hline Health sciences & 161 & 11.0 & 42 & 26.2 & 119 & 73.9 & & \\
\hline Science and humanities & 273 & 18.6 & 58 & 21.2 & 215 & 78.8 & & \\
\hline Vocational high school & 119 & 8.1 & 74 & 37.8 & 45 & 62.2 & & \\
\hline \multicolumn{9}{|l|}{ Who are they living with? } \\
\hline Family & 580 & 39.6 & 183 & 31.6 & 397 & 68.4 & 93644 & $<0.001$ \\
\hline Friends & 327 & 22.3 & 197 & 60.2 & 130 & 39.8 & & \\
\hline Dorm & 433 & 29.6 & 151 & 34.9 & 282 & 65.1 & & \\
\hline On their own & 125 & 8.5 & 73 & 58.4 & 52 & 41.6 & & \\
\hline \multicolumn{9}{|l|}{ Income } \\
\hline Low & 345 & 23.5 & 153 & 44.3 & 192 & 55.7 & 2016 & 0.365 \\
\hline Intermediate & 644 & 44.0 & 263 & 40.8 & 381 & 59.2 & & \\
\hline High & 476 & 32.5 & 188 & 39.5 & 288 & 60.5 & & \\
\hline \multicolumn{9}{|l|}{ Frequency of changing phones } \\
\hline $0-12$ months & 40 & 2.7 & 23 & 57.5 & 17 & 42.5 & 6335 & 0.096 \\
\hline $1-2$ years & 320 & 21.8 & 140 & 43.8 & 180 & 56.2 & & \\
\hline 3-4 years & 780 & 53.2 & 307 & 39.4 & 473 & 60.2 & & \\
\hline 5 years and above & 325 & 22.2 & 134 & 58.8 & 191 & 41.2 & & \\
\hline \multicolumn{9}{|l|}{ Monthly phone bill } \\
\hline Low & 150 & 10.2 & 66 & 44.0 & 84 & 56.0 & 7937 & 0.047 \\
\hline Intermediate & 860 & 58.7 & 331 & 38.5 & 529 & 61.5 & & \\
\hline High & 306 & 20.9 & 145 & 47.4 & 161 & 52.6 & & \\
\hline Very high & 149 & 10.2 & 62 & 41.6 & 87 & 58.4 & & \\
\hline Smartphone addiction & 687 & 46.9 & 277 & 40.3 & 410 & 59.7 & 0.441 & 0.507 \\
\hline
\end{tabular}

BMI: Body mass index, Economics/administr.: Faculty of economics and administrative sciences, SD: Standard deviation, t: Student t test, $\chi^{2}$ : Chi-squared test

\section{DISCUSSION}

Our study examined smartphone use characteristics and purposes that may predict smartphone addiction in university students. Our findings indicate that using phones for "social media use" and "meeting new friends" increases the smartphone addiction risk, while "use for studying/academic purpose" and "following 
the news" reduce that risk. Another important finding of our study is the fact that male students use their smartphone more for "playing games," "meeting new friends," and "following the news" than their female counterparts. To our knowledge, our study is the first one to examine the correlation between smartphone use profiles and smartphone addiction in a population of university students.

According to a behaviorist approach, if a behavior leads to gratification and/or relief and/or if it detracts from negative situations like tension or distress, an individual will continue with this behavior or increase it to feel gratification/pleasure and/or avoid negative situations (15). From this perspective, a person might use the smartphone to avoid a negative environment and/or to feel pleasure. On the other hand, it is interesting to ask if the addictive effect of the everpresent smartphone lies in the device itself, in the purposes for its use (games, gambling, social media, messaging), or in its applications.

Studies on smartphone addiction found social media use, playing games, and use for entertainment to be predictive of smartphone addiction, while academic use was not found to be predictive $(12,13)$. In line with earlier work, our study found that the purposes "social media use" and "meeting new friends" increased the risk of smartphone addiction in the overall population, while "use for studying/academic purpose" and "following the news" reduced the risk of addiction in the whole population. In addition, our study showed that using the smartphone to "play games" increased the addiction risk in female students, while smartphone use for entertainment increased the risk in male students. We believe that these findings are first in the literature. Our results show that the main modality of using smartphones is to access social media, and this use is the one that leads to the greatest increase in the addiction risk. In addition, the small size of smartphone screens may reduce its usefulness and enjoyment for the intended purpose. Therefore, there may be a preference for devices with a bigger screen for playing games, academic use, shopping, and entertainment (16).

Chen et al. (17) have shown that men and women use smartphones for different purposes: while men more often play games and seek entertainment, women use the phone more for messaging and social media. According to our results, males use the smartphone more for "playing games," "meeting new friends," and "following the news" than females. In contrast to the literature, we found no difference between female and male students for "social media use," "entertainment," and "messaging." The most likely explanation for this divergent result could be the cultural difference between the samples, as in Turkey male students are using social media and communication as much as females do. In addition, our study also found no difference between female and male students for "studying/academic purpose" and "entertainment."

Despite the large study sample, we need to assess the study in the light of certain limitations. First of all, the participants are all university students and thus do not represent the population as a whole. We need studies with participants from different age groups and with a different education background. Secondly, as all measurements and data were collected using self-report instruments, data are open to fudging. Thirdly, a crosssectional design is not the best method to assess causal relations. Fourth, the distinction between different purposes for smartphone use may not be so clear. For example, some types of social media provide entertainment content or allow playing games. Future studies should take possible overlap between content

Table 2: Evaluation of the purpose of phone use by sex

\begin{tabular}{|c|c|c|c|c|c|c|c|c|}
\hline & \multicolumn{2}{|c|}{ Total } & \multicolumn{2}{|c|}{ Male } & \multicolumn{2}{|c|}{ Female } & \multirow[b]{2}{*}{$\chi^{2}$} & \multirow[b]{2}{*}{$\mathbf{p}$} \\
\hline & $\mathbf{n}$ & $\%$ & $\mathbf{n}$ & $\%$ & $\mathbf{n}$ & $\%$ & & \\
\hline Social media use & 1212 & 82.7 & 501 & 41.3 & 711 & 58.7 & 0.034 & 0.854 \\
\hline Use for studying/academic purpose & 893 & 61.0 & 359 & 40.2 & 534 & 59.8 & 0.996 & 0.318 \\
\hline Use for playing games & 512 & 34.9 & 269 & 52.5 & 243 & 47.5 & 41553 & $<0.001$ \\
\hline To meet new friends & 319 & 21.8 & 187 & 58.6 & 132 & 41.4 & 50907 & $<0.001$ \\
\hline Use for communication & 1199 & 81.8 & 488 & 40.7 & 711 & 59.3 & 0.760 & 0.383 \\
\hline $\begin{array}{l}\text { For entertainment (watching series, } \\
\text { movies, clips) }\end{array}$ & 648 & 44.2 & 249 & 38.4 & 399 & 61.6 & 3767 & 0.052 \\
\hline To follow the news & 814 & 55.6 & 365 & 44.8 & 449 & 55.2 & 9861 & 0.002 \\
\hline For shopping & 530 & 36.2 & 204 & 38.5 & 326 & 61.5 & 2569 & 0.109 \\
\hline
\end{tabular}

$\chi^{2}$ : Chi-squared test 


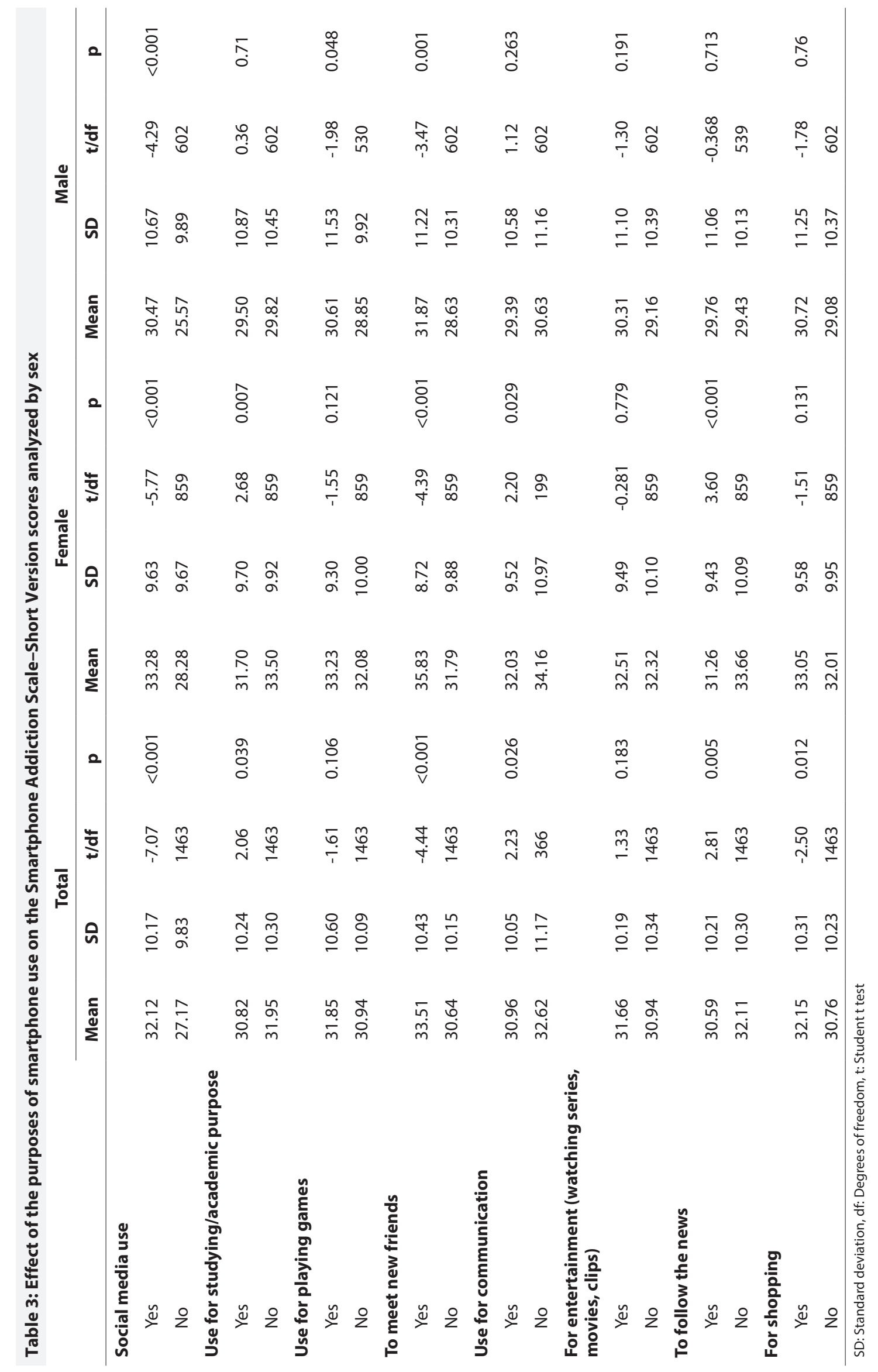


Table 4: Demonstration of the effect of the purposes of smartphone use on smartphone addiction using logistic regression

Odds ratio

\section{All students}

Social media use

Use for studying/academic purpose

Use for playing games

To meet new friends

Use for communication

For entertainment (watching series, movies, clips)

To follow the news

For shopping

\section{Female students}

Social media use

Use for studying/academic purpose

Use for playing games

To meet new friends

Use for communication

For entertainment (watching series, movies, clips)

To follow the news

For shopping

\section{Male students}

Social media use

Use for studying/academic purpose

Use for playing games

To meet new friends

Use for communication

For entertainment (watching series, movies, clips)

To follow the news

For shopping

: Significance was accepted at $p<0.05$

categories into account. On the other hand, the literature in this field is not yet rich enough. Finally, we used an SAS-SV cutoff point established in a Korean sample for the diagnosis of smartphone addiction, which is another limitation of our study.

Considering the high prevalence of smartphone addiction among university students found in our study, we suggest that smartphone addiction is a public health issue in Turkey. This study considers the correlation between certain purposes for the use of smartphones and smartphone addiction. We found that social media use and meeting new friends increased the students' addiction risks the most, while "use for studying/ academic purpose" and "following the news" reduced the addiction risk. As our study emphasized sex-differences in smartphone addiction, we suggest that a preventive
95\% confidence interval

$\mathbf{p}$

$\begin{array}{llll}2.884 & 2.085 & 3.099 & <0.001 \\ 0.589 & 0.434 & 0.797 & 0.001 \\ 1.214 & 0.933 & 1.580 & 0.150 \\ 2.066 & 1.535 & 2.783 & <0.001 \\ 0.925 & 0.675 & 1.167 & 0.626 \\ 1.199 & 0.915 & 1.570 & 0.188 \\ 0.645 & 0.485 & 0.857 & 0.002 \\ 0.946 & 0.710 & 1.260 & 0.704\end{array}$

3.719

2.403

5.755

$<0.001$

0.533

0.352

0.003

1.447

1.011

0.805

0.043

2.174

1.410

$<0.001$

0.967

0.629

2.073

0.879

0.990

0.688

0.955

0.559

0.386

0.002

0.834

0.567

0.810

0.354

2.138

1.299

3.516

0.003

0.634

0.401

1.004

0.052

1.018

0.677

1.530

0.933

2.094

1.359

3.226

0.001

0.839

0.522

1.350

0.470

1.544

1.022

2.332

0.039

0.878

0.558

1.383

0.575

1.051

0.672

1.643

0.827

and interventional strategy to reduce this behavioral problem should be multifactorial and sex-specific.

\begin{tabular}{|c|c|c|}
\hline \multicolumn{2}{|c|}{ Contribution Categories } & \multirow{2}{*}{$\begin{array}{l}\text { Author Initials } \\
\text { D.A.C., I.G. }\end{array}$} \\
\hline \multirow{3}{*}{ Category 1} & Concept/Design & \\
\hline & Data acquisition & I.G. \\
\hline & Data analysis/Interpretation & D.A.C., I.G. \\
\hline \multirow{2}{*}{ Category 2} & Drafting manuscript & I.G. \\
\hline & Critical revision of manuscript & D.A.C., I.G. \\
\hline Category 3 & Final approval and accountability & D.A.C., I.G. \\
\hline \multirow{2}{*}{ Other } & Technical or material support & D.A.C. \\
\hline & Supervision & N/A \\
\hline
\end{tabular}

Ethics Committee Approval: Approval from the local ethics committee was obtained before beginning the study, and all volunteers gave their consent before completing the survey. 
Informed Consent: Written informed consent was obtained from the patient for the publication of the case report and the accompanying images.

Peer-review: Externally peer-reviewed.

Conflict of Interest: No conflict of interest.

Financial Disclosure: The authors declare no financial support.

\section{REFERENCES}

1. Deloitte. Deloitte Global Mobile Phone Use Research 2017, 2018. https://www2.deloitte.com/tr/tr/pages/about-deloitte/articles/ deloitte-global-mobil-kullaici-arastirmasi-2017.html. Accessed May 2, 2019. (Turkish)

2. Akilli GK, Gezgin DM. Examination of relationship between university students' nomophobia levels and behavior patterns. Mehmet Akif Ersoy University Journal of Education Faculty 2016; 40:51-69. (Turkish)

3. Kwon M, Lee JY, Won WY, Park JW, Min JA, Hahn C, Gu X, Choi JH, Kim DJ. Development and validation of a smartphone addiction scale (SAS). PloS one 2013; 8:e56936.

4. Kwon M, Kim DJ, Cho H, Yang S. The smartphone addiction scale: development and validation of a short version for adolescents. PloS One 2013; 8:e83558.

5. Chen B, Liu F, Ding S, Ying X, Wang L, Wen Y. Gender differences in factors associated with smartphone addiction: a cross-sectional study among medical college students. BMC Psychiatry 2017; 17:341.

6. Lee H, Ahn H, Choi S, Choi W. The SAMS: Smartphone addiction management system and verification. J Med Syst 2014; $38: 1$.

7. Mok JY, Choi SW, Kim DJ, Choi JS, Lee J, Ahn H, Choi EJ, Song WY. Latent class analysis on internet and smartphone addiction in college students. Neuropsychiatr Dis Treat 2014; 10:817-828.
8. Demirci K, Akgonul M, Akpinar A. Relationship of smartphone use severity with sleep quality, depression, and anxiety in university students. J Behav Addict 2015; 4:85-92.

9. Mohammadbeigi A, Absari R, Valizadeh F, Saadati M, Sharifimoghadam S, Ahmadi A, Mokhtari M, Ansari H. Sleep quality in medical students; the impact of over-use of mobile cell-phone and social networks. J Res Health Sci 2016; 16:46-50.

10. Mattila AK, Luutonen S, Ylinen M, Salokangas RK, Joukamaa M. Alexithymia, human relationships, and mobile phone use. J Nerv Ment Dis 2010; 198:722-727.

11. Noyan CO, Enez Darcin A, Nurmedov S, Yilmaz O, Dilbaz N. Validity and reliability of the Turkish version of the Smartphone Addiction Scale-Short Version among university students. Anatolian Journal of Psychiatry 2015; 16 (Special issue 1):73-81. (Turkish)

12. Jeong SH, Kim H, Yum JY, Hwang Y. What type of content are smartphone users addicted to?: SNS vs. games. Comput Human Behav 2016; 54:10-17.

13. Liu $\mathrm{CH}$, Lin SH, Pan YC, Lin YH. Smartphone gaming and frequent use pattern associated with smartphone addiction. Medicine (Baltimore) 2016; 95:e4068.

14. Alosaimi FD, Alyahya H, Alshahwan H, Al Mahyijari N, Shaik SA. Smartphone addiction among university students in Riyadh, Saudi Arabia. Saudi Med J 2016; 37:675-683.

15. Cuceloglu D. Humans and Their Behavior. Istanbul: Remzi Kitabevi, 2015. (Turkish)

16. Hou J, Nam Y, Peng W, Lee KM. Effects of screen size, viewing angle, and players' immersion tendencies on game experience. Comput Human Behav 2012; 28:617-623.

17. Chen B, Liu F, Ding S, Ying X, Wang L, Wen Y. Gender differences in factors associated with smartphone addiction: a cross-sectional study among medical college students. BMC Psychiatry 2017; 17:341. 